Check for updates

Cite this: RSC Adv., 2018, 8, 38598

Received 5th October 2018

Accepted 8th November 2018

DOI: $10.1039 / c 8 r a 08241 c$

rsc.li/rsc-advances

\section{Synthesis and fluorescent properties of boroisoquinolines, a new family of fluorophores $\uparrow$}

\author{
Dénes Sóvári, ${ }^{a}$ Attila Kormos, (DD b Orsolya Demeter, ${ }^{\mathrm{b}}$ András Dancsó, (D) \\ György Miklós Keserü, (D) a Mátyás Milen ${ }^{c}$ and Péter Ábrányi-Balogh (D) *a
}

First representatives of a new family of isoquinolines, so called boroisoquinolines, were synthesized and characterized. The synthesis was based on the insertion of the difluoroboranyl group into the 1methylidene-3,4-dihydroisoquinoline core. The optimization of the 2-difluoroboranyl-3,4dihydroisoquinoline-1(2H)-ylidene core led to efficient fluorescence in a range of 400-600 nm with outstanding (>100 nm) Stokes shifts. The compounds might be suitable for reversible or irreversible labelling of proteins, particularly the cannabinoid receptor $\mathrm{CB}_{2}$.

\section{Introduction}

The isoquinoline core is represented in a large number of biologically active compounds containing alkaloids and also synthetic heterocycles (Fig. 1). The alkaloids can be found widely in various plants ${ }^{1-4}$ and marine invertebrates. ${ }^{5}$ A well-known pharmacologically significant compound is papaverine (1) that was isolated from opium poppies (Papaver somniferum) and was used as a smooth muscle relaxant. ${ }^{6}$ Other biologically active representatives are the members of the berberine (2) family that were isolated from various herbs. ${ }^{7,8}$ These plants (e.g. Coptis chinensis) have been used in traditional Chinese medicine for the treatment of infections, skin problems and diabetes. ${ }^{9-12}$ Among the latter compounds palmatine (3) should be mentioned as a widely used tetracyclic isoquinoline against, among others, hypertension and inflammation. ${ }^{13}$ From a marine sponge Jaspis sp. also, more complex isoquinoline natural products were isolated such as jasisoquinoline $\mathrm{A}$ and $B$ ( $\mathbf{4 a}$ and $\mathbf{4 b}$, respectively) that possess anticancer activity. ${ }^{\mathbf{1 4}}$ Ripasudil (5, Glanatec $\left.{ }^{\circledR}\right)$ activates the Rho-kinase, hence it is used in the treatment of glaucoma and increased eye-pressure. ${ }^{15,16}$ Furthermore, many isolated or synthesized isoquinoline derivatives exhibit a vast spectrum of biological activities including antiHIV,${ }^{17}$ antitubercular, ${ }^{18}$ antiplasmodial, ${ }^{19}$ anti-Alzheimer's ${ }^{20}$ and antifungal effects ${ }^{21}$ and some representatives are non-competitive

${ }^{a}$ Hungarian Academy of Sciences, Research Centre for Natural Sciences, Institute of Organic Chemistry, Medicinal Chemistry Research Group, 1519 Budapest, POB 286, Hungary. E-mail: abranyi-balogh.peter@ttk.mta.hu; Tel: +36 13826961

${ }^{b}$ Hungarian Academy of Sciences, Research Centre for Natural Sciences, Institute of Organic Chemistry, Chemical Biology Research Group, 1519 Budapest, POB 286, Hungary

${ }^{c}$ Egis Pharmaceuticals Plc., Directorate of Drug Substance Development, 1475 Budapest, $P O B$ 100, Hungary

$\dagger$ Electronic supplementary information (ESI) available: Experimental, spectroscopy and XRD data. For experimental procedures and compound characterization. CCDC 1854624 and 1854625 . For ESI and crystallographic data in CIF or other electronic format see DOI: 10.1039/c8ra08241c
AMPA [2-amino-3-(3-hydroxy-5-methylisoxazol-4-yl)propionic acid] receptor antagonists. ${ }^{22}$ In addition, the commercially available drug solifenacin (Vesicare $\left.{ }^{\circledR}, 6\right)$, a 1-aryl-tetrahydroisoquinoline derivative shows competitive cholinergic receptor antagonist effect used in the treatment of contraction of overactive bladder. $^{23,24}$ Members of the 2'-(3,3-dimethyl-3,4dihydroisoquinoline-1-ylidene)-1-ethane-1-one family (7) should be mentioned as non-toxic and specific nanomolar $\mathrm{CB}_{2}$ agonist, while other derivatives of this family can inhibit phosphodiesterase 7 (PDE7). On this basis, these compounds might be considered as preventive or treating agents for asthma, autoimmune diseases, rheumatoid arthritis, Crohn's disease or carcinomatous pain..$^{25-28}$ Besides the pharmaceutical applications, isoquinoline derivatives were also utilized as chiral ligands for catalytic asymmetric reactions ${ }^{29}$ or as electrophosphorescent iridium complexes. ${ }^{30}$ Boranyls (8) and related compounds containing nitrogen-boron-oxygen structural element (NBOcomplexes) are a recently developed family of fluorescent molecules (Fig. 2). The photophysical properties of several known NBOcomplexes are summarized in Table 1 . These compounds were designed to overcome the drawbacks of BODIPY's e.g. small Stokes-shift, difficult industrial synthesis. ${ }^{31}$ The synthesis of boranyls is usually starting from an imino compound containing a hydroxyl or an enolizable oxo group at the $\gamma$-position. The parent compounds are reacted with a trisubstituted borane, mostly $\mathrm{BF}_{3}$ or $\mathrm{B}(\operatorname{aryl})_{3}$ resulting in a disubstituted borane group inserted between the nitrogen and the oxygen atom. The photophysical characterization of these compounds showed acceptable Stokes-shifts with good $\varepsilon$ and $\Phi$ values (Table 1, entry 1). ${ }^{32}$ It was observed that in the case of borobenzothiazoles $^{33}$ (9) a push-pull system between a disubstituted amino and a nitrile group was required for an outstanding Stokes-shift (149-170 nm, entry 2), but the quantum yield of the compounds was weak. Minuti and co-workers designed boranyls for biological application by the ring opening of isoxazoles to 10 equipped with an acetylene tail in order to the click 
<smiles>COc1ccc(Cc2nccc3cc(OC)c(OC)cc23)cc1OC</smiles><smiles></smiles><smiles></smiles><smiles>C[C@H]1CNCCCN1S(=O)(=O)c1cccc2cncc(F)c12</smiles><smiles>O=C(O[C@H]1CN2CCC1CC2)N1CCc2ccccc2[C@H]1c1ccccc1</smiles><smiles>[R]C(=C)/C=C1\NC(C)(C)Cc2cc[R1]([H])cc21</smiles>

Fig. 1 Structures of pharmaceutically active isoquinoline derivatives.<smiles></smiles>

12<smiles></smiles>
9<smiles>[R]c1ccc2c(c1)OB(F)N1C=C2C=C(c2ccccc2)c2ccccc21</smiles>

13<smiles></smiles><smiles></smiles>

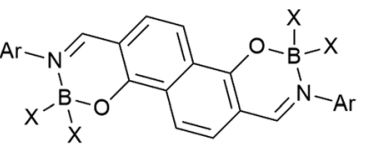

14<smiles></smiles>

15
$\mathrm{Ar}=$ aryl $\mathrm{R}=\mathrm{H}$, alkyl, $\mathrm{Hal}$, OMe, $\mathrm{NO}_{2} \mathrm{CN}, \mathrm{CH}_{2} \mathrm{OCH}_{3}$ $\mathrm{X}=\mathrm{F}, \mathrm{Ph}, \mathrm{C}_{6} \mathrm{~F}_{5}$

Fig. 2 Boranyls (8) and related compounds containing nitrogen-boron-oxygen structural element (NBO-complexes, 9-15).

labeling of azidoproteins. ${ }^{34}$ Only one member of the boranyls derived from coumarins (11) showed weak fluorescence but on the contrary, the phosphorescence of those was remarkable (Table 1, entry 3$){ }^{35}$ Boroquinolines $(\mathbf{1 2}, \mathbf{1 3})$ were synthesized from salicylic aldehyde, aniline and phenylacetylene, showing a Stokes-shift of 80-200 $\mathrm{nm}$ and green fluorescence (Table 1, entries 4, 5) ${ }^{36,37}$ From naphthalene dialdehyde multiboranyls (14) were synthesized, but the larger molecule size caused lower fluorescence. ${ }^{38}$ Nevertheless, a nice red shift was obtained with a wide range of quantum yield (Table 1, entry 6). Related compounds, so called polyboranyls (15) were designed from $m$-phthalic aldehyde exhibiting large Stokesshift with medium molar absorptivity and quantum yield (Table 1 , entry 7). ${ }^{39}$
As a continuation of our efforts on the field of developing biologically interesting isoquinoline derivatives, ${ }^{40}$ the objective of our work was the synthesis of new fluorescent members of the 2'-(3,4-dihydroisoquinoline-1-ylidene)-1-ethan-1-one (7) family equipped with $\mathrm{BR}_{2}$ groups.

\section{Results and discussion}

The fluorescent molecules were envisaged to be obtained by the acylation of dihydroisoquinolines followed by the incorporation of a boranyl group. Initially, the starting 7-methoxy (16a), 6,7dimethoxy (16b), 7-bromo (16c) and 7-fluoro-3,4dihydroisoquinoline (16d) have been synthesized by slight

Table 1 Photophysical properties of NBO-complexes

\begin{tabular}{|c|c|c|c|c|c|c|c|}
\hline Entry & & Solvent & $\lambda_{\mathrm{absz}}^{\max }[\mathrm{nm}]$ & $\lambda_{\mathrm{em}}^{\max }[\mathrm{nm}]$ & Stokes-shift [nm] & $\varepsilon\left[\mathrm{M}^{-1} \mathrm{~cm}^{-1}\right]$ & $\Phi_{\mathrm{F}}[-]$ \\
\hline 1 & $8^{32}$ & $\mathrm{CH}_{2} \mathrm{Cl}_{2}$ & $344-387$ & $380-432$ & $14-68$ & $13100-67200$ & $0.22-0.73$ \\
\hline 2 & $9^{33}$ & $\mathrm{MeCN}$ & $442-450$ & $599-612$ & $149-170$ & - & $0.004-0.008$ \\
\hline 3 & $11^{35 a}$ & THF/dioxane & 331 & 420 & 89 & 33660 & - \\
\hline 4 & $12^{36}$ & $\mathrm{CHCl}_{3}$ & $385-417$ & $523-543$ & $126-145$ & 8317-11482 & $0.18-0.32$ \\
\hline 5 & $13^{37}$ & $\mathrm{CHCl}_{3}$ & $288-385$ & $467-538$ & $82-201$ & $14300-38500$ & $0-0.22$ \\
\hline 6 & $14^{38}$ & $\mathrm{CH}_{2} \mathrm{Cl}_{2}$ & $495-589$ & $457-609$ & $37-183$ & $17300-148700$ & $0-0.56$ \\
\hline 7 & $15^{39}$ & $\mathrm{CH}_{2} \mathrm{Cl}_{2}$ & $495-589$ & $533-683$ & $38-101$ & $13100-44500$ & $0-0.81$ \\
\hline
\end{tabular}

${ }^{a}$ Only one member showed fluorescence. 


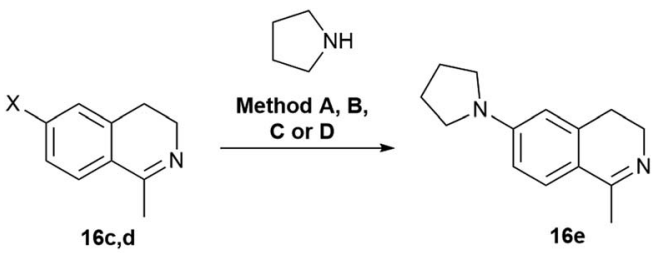

\begin{tabular}{c|c|c|c|c|c} 
Method & $\mathrm{X}$ & Additives & Solvent & $\mathrm{T}, \mathrm{t}$ & Yield \\
\hline A & $\mathrm{Br}$ & $\begin{array}{c}\mathrm{Pd}(\mathrm{OAC})_{2,} \\
\text { JohnPhos, } \\
\mathrm{KOt}-\mathrm{Bu}\end{array}$ & $\mathrm{PhMe}$ & $80^{\circ} \mathrm{C}, 1 \mathrm{~h}$ & $40 \%$ \\
B & $\mathrm{F}$ & - & - & $80^{\circ} \mathrm{C}, 18 \mathrm{~h}$ & $40 \%$ \\
C & $\mathrm{F}$ & - & $\mathrm{MeCN}$ & $80^{\circ} \mathrm{C}, 9 \mathrm{~d}$ & $42 \%$ \\
D & $\mathrm{F}$ & - & dioxane & $120^{\circ} \mathrm{C}, 3 \mathrm{~d}$ & $70 \%$
\end{tabular}

Scheme 1 The synthesis of 1-methyl-7-pyrrolidine-1-yl-3,4-dihydroisoquinoline (16e).

modification of literature procedures. ${ }^{41,42}$ In most cases, the corresponding phenylacetonitriles were transformed to phenylethylamines using borane in $\mathrm{THF}^{43}$ followed by the acylation with acetyl chloride. The ring closure was achieved with a modified Bischler-Napieralski reaction after Larsen using oxalyl chloride in the presence of $\mathrm{FeCl}_{3}$ and the subsequent reaction with sulphuric acid in $\mathrm{MeOH}{ }^{44}$ In the case of 7pyrrolidinyl-1-methyl-3,4-dihydroisoquinoline (16e), the pyrrolidine group was inserted either with Buchwald-Hartwig reaction of $16 \mathrm{c}$ or with the aromatic nucleophilic substitution of $\mathbf{1 6 d}$ (Scheme 1).

The Buchwald-Hartwig coupling was performed in the presence of $\mathrm{Pd}(\mathrm{OAc})_{2}$, JohnPhos and $\mathrm{KO}$-Bu in toluene leading to $16 \mathrm{e}$ in a yield of $40 \%$ (Scheme 1, Method A). ${ }^{45}$ In order to improve the outcome, several substitution reactions were tried using $16 d$ (Method B, C and D). ${ }^{46,47}$ The best result was obtained reacting $16 \mathrm{~d}$ with 6 equiv. of pyrrolidine in dioxane at $120{ }^{\circ} \mathrm{C}$ in a sealed tube for 3 days resulting in 16e in a yield of $70 \%$ (Method D). Notably, for the purification of 16e steam distillation and normal phase flash chromatography was required.

The synthesis of the 1-methylidene-1,2,3,4tetrahydroisoquinolines (17) was accomplished by the slight modification of the method of Dannhardt et al. using BuLi or lithium-diisopropylamide (LDA) to deprotonate the methyl group of the 1-methyl-3,4-dihydroisoquinolines (16a-e) derivatives followed by the addition of the appropriate ester (Scheme
Table 2 Results for the synthesis of 1-methylidene-1,2,3,4-tetrahydroisoquinolines (17) and boroisoquinolines 18, 21

\begin{tabular}{llllllll}
\hline$\#$ & & $\mathrm{R}^{1}$ & $\mathrm{R}^{2}$ & $\mathrm{R}^{3}$ & $\mathbf{1 7}^{a}[\%]$ & $\mathbf{1 8}^{a}[\%]$ & $\mathbf{1 9}^{a}[\%]$ \\
\hline 1 & $\mathbf{a}$ & $\mathrm{MeO}$ & $\mathrm{H}$ & $\mathrm{Me}$ & 46 & 77 & 73 \\
2 & $\mathbf{b}$ & $\mathrm{MeO}$ & $\mathrm{MeO}$ & $\mathrm{Me}$ & 50 & 78 & 70 \\
3 & $\mathbf{c}$ & $\mathrm{MeO}$ & $\mathrm{H}$ & $\mathrm{Ph}$ & 45 & 70 & 77 \\
4 & $\mathbf{d}$ & $\mathrm{MeO}$ & $\mathrm{MeO}$ & $\mathrm{Ph}$ & 53 & 88 & 89 \\
5 & $\mathbf{e}$ & $\mathrm{MeO}$ & $\mathrm{H}$ & $2-\mathrm{Thienyl}$ & 58 & 50 & 52 \\
6 & $\mathbf{f}$ & $\mathrm{MeO}$ & $\mathrm{MeO}$ & $2-\mathrm{Thienyl}^{2}$ & 48 & 85 & 48 \\
7 & $\mathbf{g}$ & $\mathrm{MeO}$ & $\mathrm{H}$ & $\mathrm{C}_{6} \mathrm{~F}_{5}$ & 12 & 85 & - \\
8 & $\mathbf{h}$ & $\mathrm{MeO}$ & $\mathrm{MeO}$ & $\mathrm{C}_{6} \mathrm{~F}_{5}$ & 57 & 89 & - \\
9 & $\mathbf{i}$ & $\mathrm{MeO}$ & $\mathrm{H}$ & $4-\mathrm{O}_{2} \mathrm{~N}-\mathrm{C}_{6} \mathrm{H}_{4}$ & 5 & - & - \\
10 & $\mathbf{j}$ & $\mathrm{MeO}$ & $\mathrm{MeO}$ & $4-\mathrm{O}_{2} \mathrm{~N}-\mathrm{C}_{6} \mathrm{H}_{4}$ & $54(3)^{b}$ & 49 & - \\
11 & $\mathbf{k}$ & $\mathrm{Py}$ & $\mathrm{H}$ & $\mathrm{Me}^{c}$ & $41(26)^{b}$ & 78 & - \\
12 & $\mathbf{1}$ & $\mathrm{Py}$ & $\mathrm{H}$ & $\mathrm{Ph}^{c}$ & $72(27)^{b}$ & 97 & - \\
13 & $\mathbf{m}$ & $\mathrm{Py}^{c}$ & $\mathrm{H}$ & $\mathrm{C}_{6} \mathrm{~F}_{5}$ & $20(16)^{b}$ & 81 & -
\end{tabular}

${ }^{a}$ Isolated yields. ${ }^{b}$ Yields with LDA, results with BuLi are in parentheses. ${ }^{c}$ Pyrrolidine-1-yl.

$2)^{48}$ Heterocycles $17 \mathbf{a}-\mathbf{h}$ were isolated in moderate yields (12$65 \%$, Table 2, entries 1-8). In the case of 4-nitrobenzoic acid ethyl ester, the products $(\mathbf{1 7 i}, \mathbf{j})$ could be isolated in traces with BuLi (3-5\%), but using LDA the yield of $\mathbf{1 7} \mathbf{j}$ was raised to $54 \%$ (Table 2, entries 9, 10). Changing the methoxy group on the isoquinoline to pyrrolidine also lowered the yields (16-27\%) possibly due to the interaction of the pyrrolidine nitrogen with the BuLi. The use of a larger amount of BuLi, or changing the base to sec-BuLi or BuLi-TMEDA did not give better results, but again, the application of LDA led to a significant raise in the isolated yields (20-72\%, Table 2, entries 11-13).

The difluoro-boroisoquinoline structure (18) was constructed by reacting compounds 17 with boron trifluoride diethyl etherate in the presence of 5 equiv. of diisopropylethylamine (DIPEA) in dichloromethane (Scheme 2). ${ }^{32}$ In order to synthesize fully aromatic derivatives with respect to its expected advantageous effect on the fluorescence, compounds 18a-f were dehydrogenated with $\mathrm{Pd} / \mathrm{C}$ in dioxane at $200{ }^{\circ} \mathrm{C}$ for $90 \mathrm{~min}$ (Scheme 2). Boroisoquinolines 19a-f were isolated in good yields (48-89\%, Table 2, entries 16). In the case of $\mathbf{1 8 k}-\mathbf{m}$, the pyrrolidine ring was aromatized during the reaction, a selective oxidation could not be developed. Dehydrogenating derivatives with $\mathrm{C}_{6} \mathrm{~F}_{5}$ substituent produced only degradation products that could be detected by HPLC-MS with loss of various fluorine atoms. In the case of $\mathbf{1 8 j}$, the nitro group was converted to amino function, and decomposition products were observed.

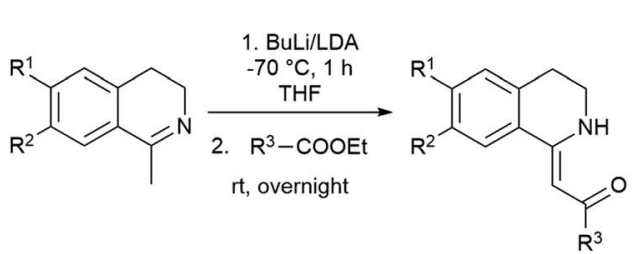

16a-e

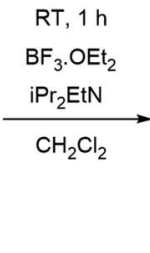

$17 \mathrm{a}-\mathrm{m}$<smiles>[R]C(=O)/C=C1/c2cc([R])c([R])cc2CCN1B(F)F</smiles>

$18 \mathrm{a}-\mathrm{m}$

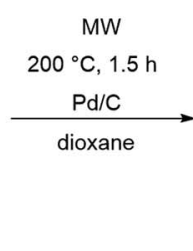

C, $1.5 \mathrm{~h}$<smiles>[R]C(=O)/C=C1\c2cc([R])c([Z])cc2C=C[NH+]1[PH-](F)F</smiles>

19a-f

Scheme 2 Synthesis of 1-methylidene-1,2,3,4-tetrahydroisoquinolines (17) and boroisoquinolines 18 and 19. 


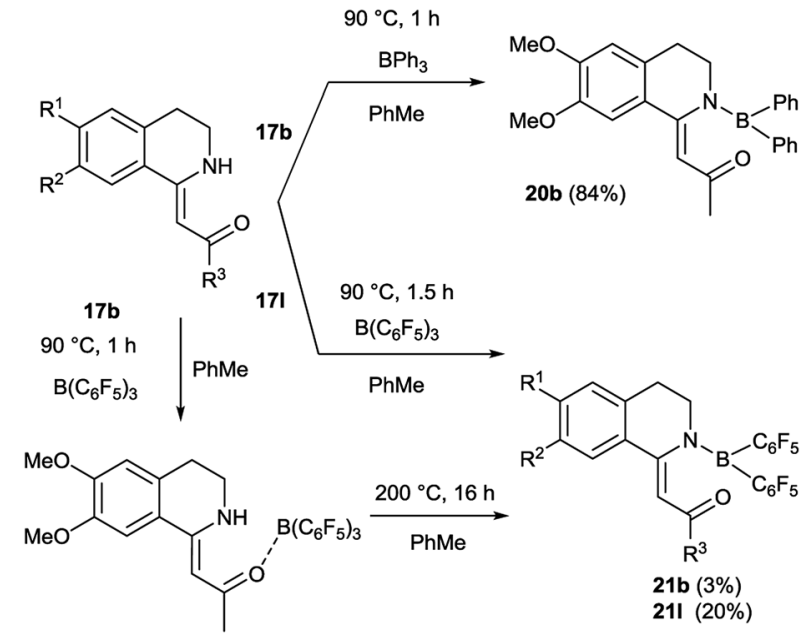

22b (41\%)

Scheme 3 Synthesis of boroisoquinolines 20, 21, 22
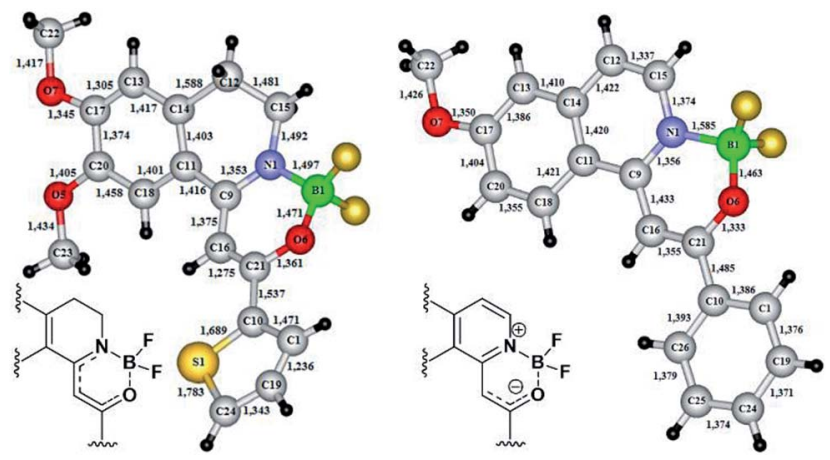

Fig. 3 X-ray structures of boroisoquinolines $18 \mathrm{f}$ and $19 \mathrm{c}$.
We aimed to synthesize further boranyl derivatives using triaryl boranes. A diphenyl-boroisoquinoline (20b) was prepared in a yield of $84 \%$ by refluxing $\mathbf{1 7 b}$ with triphenylborane in toluene at $90{ }^{\circ} \mathrm{C}$ (Scheme 3$) .{ }^{31}$ In the case of $\mathrm{B}\left(\mathrm{C}_{6} \mathrm{~F}_{5}\right)_{3}$ as the borylating agent, the formation of the desired bis(perfluorophenyl)-boroisoquinoline was observed depending on the starting compound either in a one-step reaction in toluene at $90{ }^{\circ} \mathrm{C}$ leading to 211 in a yield of $20 \%$, or in a two-step procedure through the heating of tris(perfluorophenyl)borosisoquinoline intermediate $22 \mathrm{~b}$ at $200{ }^{\circ} \mathrm{C}$ resulting in $\mathbf{2 1 b}$ in a poor yield (3\%) (Scheme 3$)$.

In the cases of $\mathbf{1 8 f}$ and $19 \mathrm{c}$ the exact structure of the new heterocyclic family members was elucidated by single crystal Xray diffraction measurements (Fig. 3). From the crystal structures it could be concluded, that until the nitrogen atom of $\mathbf{1 8 f}$ has pyramidal conformation, in 19c the nitrogen is planar. The bond lengths proved the boron-nitrogen bonding and the boron-oxygen coordination. The proposed electrondistribution and bonding in the NBO containing ring is shown on the figures next to the crystal structures. Representative bond lengths and bond angles are shown in Table 3. The detailed XRD data and ORTEP figures can be found in the ESI. $\dagger$

The synthesis was followed by the extensive photophysical analysis of the new boroisoquinolines. The absorbance and fluorescence spectra were measured for compounds $\mathbf{1 8 a}-\mathbf{h}, \mathbf{k}-\mathbf{m}$, 19a-f, 20b, 21b,1 and 22b (Table 4) in acetonitrile. It should be noted, that the nitro group of $\mathbf{1 8 \mathbf { j }}$ was disadvantageous for the fluorescence, as the intensity was measured in the range of the noise.

Regarding the different boranyls, although $\lambda^{\text {max }}$-s of the dior triarylboranyl derivatives (20b, 21b,1, 22b, Table 4, entries 7, 13-15) were uniformly higher than those of the difluoroboranyls, the Stokes-shift did not raise or even decreased. This observation has led to the conclusion that the fluoro derivatives should be developed further and this was supported by sterical

Table 3 Representative bond lengths and bond angles

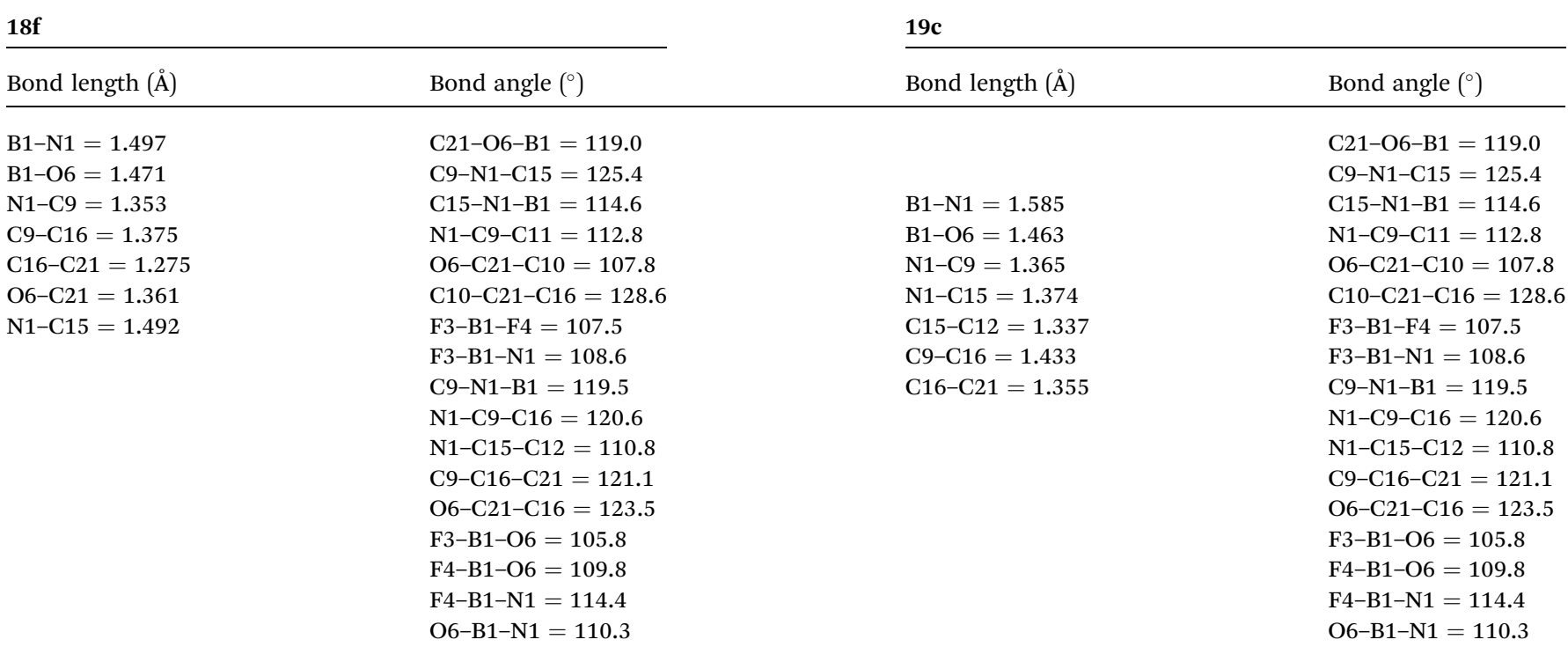


Table 4 Photophysical properties of the boroisoquinolines

\begin{tabular}{|c|c|c|c|c|c|c|c|c|c|}
\hline Entry & & $\mathrm{R}^{1 a}$ & $\mathrm{R}^{2}$ & $\mathrm{R}^{3}$ & $\mathrm{BX}$ & $\lambda_{\mathrm{abs}}^{\max }[\mathrm{nm}]$ & $\lambda_{\mathrm{exc}}^{\max }[\mathrm{nm}]$ & $\lambda_{\mathrm{em}}^{\max }[\mathrm{nm}]$ & $\begin{array}{l}\Delta \lambda \\
{[\mathrm{nm}]}\end{array}$ \\
\hline 1 & $18 \mathrm{a}$ & $\mathrm{MeO}$ & $\mathrm{H}$ & $\mathrm{Me}$ & $\mathrm{BF}_{2}$ & 328 & & 390 & 62 \\
\hline 3 & $18 k$ & Py & $\mathrm{H}$ & $\mathrm{Me}$ & $\mathrm{BF}_{2}$ & 383 & 379 & 450 & 67 \\
\hline 4 & $18 \mathrm{c}$ & $\mathrm{MeO}$ & $\mathrm{H}$ & $\mathrm{Ph}$ & $\mathrm{BF}_{2}$ & 357 & & 411 & 54 \\
\hline 5 & 18d & $\mathrm{MeO}$ & $\mathrm{MeO}$ & $\mathrm{Ph}$ & $\mathrm{BF}_{2}$ & 361 & 380 & 483 & 122 \\
\hline 8 & $18 \mathrm{e}$ & $\mathrm{MeO}$ & $\mathrm{H}$ & 2-Thienyl & $\mathrm{BF}_{2}$ & 374 & & 437 & 63 \\
\hline 9 & $18 f$ & $\mathrm{MeO}$ & $\mathrm{MeO}$ & 2-Thienyl & $\mathrm{BF}_{2}$ & 383 & & 448 & 65 \\
\hline 10 & $18 \mathrm{~g}$ & $\mathrm{MeO}$ & $\mathrm{H}$ & $\mathrm{C}_{6} \mathrm{~F}_{5}$ & $\mathrm{BF}_{2}$ & 334 & 343 & 435 & 101 \\
\hline 11 & $18 \mathrm{~h}$ & $\mathrm{MeO}$ & $\mathrm{MeO}$ & $\mathrm{C}_{6} \mathrm{~F}_{5}$ & $\mathrm{BF}_{2}$ & 334 & 356 & 537 & 203 \\
\hline 12 & $18 m$ & Py & $\mathrm{H}$ & $\mathrm{C}_{6} \mathrm{~F}_{5}$ & $\mathrm{BF}_{2}$ & 411 & 410 & 565 & 154 \\
\hline 13 & $20 b$ & $\mathrm{MeO}$ & $\mathrm{MeO}$ & $\mathrm{Me}$ & $\mathrm{BPh}_{2}$ & 337 & 387 & 453 & 116 \\
\hline 18 & $19 \mathrm{c}$ & $\mathrm{MeO}$ & $\mathrm{H}$ & $\mathrm{Ph}$ & $\mathrm{BF}_{2}$ & 378 & 372 & 487 & 109 \\
\hline 19 & 19d & $\mathrm{MeO}$ & $\mathrm{MeO}$ & $\mathrm{Ph}$ & $\mathrm{BF}_{2}$ & 396 & & 458 & 62 \\
\hline 20 & $19 e$ & $\mathrm{MeO}$ & $\mathrm{H}$ & 2-Thienyl & $\mathrm{BF}_{2}$ & 401 & & 471 & 70 \\
\hline 21 & $19 f$ & $\mathrm{MeO}$ & $\mathrm{MeO}$ & 2-Thienyl & $\mathrm{BF}_{2}$ & 410 & & 480 & 70 \\
\hline
\end{tabular}

factors too, namely it is presumed, that the extensive diarylboranyl group would be less favoured in a binding pocket of a protein than the smaller difluoroboranyl group.

On the isoquinoline ring electron donating substituents were chosen for the substitution envisioning that the electron donation will raise the fluorescence. This assumption was confirmed as the 6-methoxy derivatives showed the weakest fluorescence intensity and the lowest $\lambda^{\text {max }}$-s, while the insertion of a second methoxy group or changing the methoxy to pyrrolidinyl initiated significant increase in intensity and also $\lambda^{\text {max }}$-s (Table 4, entries 1-3, 4-6 and 10-12; representative spectra for $\mathbf{1 8 c , d , 1}$ shown on Fig. 4) leading the fluorescence into the $>500 \mathrm{~nm}$ range. In order to prove the electron donating effect of the pyrrolidine substituent, the fluorescence spectrum of $\mathbf{1 8 1}$ was measured in the presence of $\mathrm{HCl}$ (1 equiv.) (Fig. 4, grey spectrum) and a significant decrease of the fluorescence intensity was observed.

The pyrrolidine substituent caused strikingly good fluorescence $\lambda^{\max }$-s depending on the substituent on the carbonyl

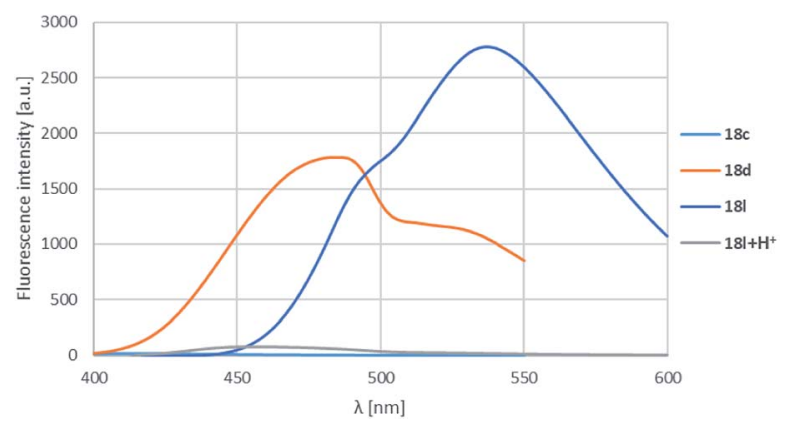

Fig. $4 R^{1}, R^{2}$ substituent effects for boroisoquinoline 18 . group. It was found that the electron donating methyl group (18k) performed best, and as the electron withdrawal was increasing from the phenyl (181) to the perfluorophenyl (18m) substituent, the fluorescence was shifted to the yellow range, but the intensity decreased significantly (Table 4, entries 3, 6, 12, Fig. 5).

The effect of the dehydrogenation was also studied, and it was found that in the case of the 6-methoxy derivatives (18a,c,e and 19a,c,e) the extension of the aromatic system was advan-

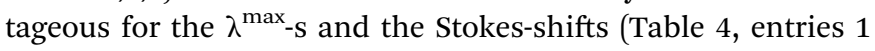
and 16,4 and 18,8 and 20 ). It should be noted, that by $19 \mathrm{c}$ a remarkable Stokes-shift $(115 \mathrm{~nm})$ was measured (Table 4 , entry 18). Meanwhile, in the case of the 6,7-dimethoxyboroisoquiolines, the oxidized species were better only for the thienyl derivative (18f and 19f, Table 4, entries 9 and 21).

The effect of various solvents for the absorbance, excitation and fluorescence was also investigated on boroisoquinoline $\mathbf{1 8 1}$

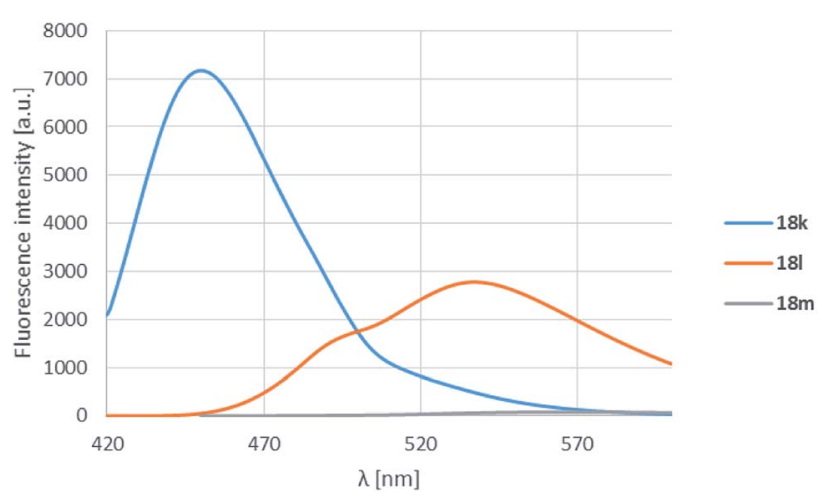

Fig. $5 \mathrm{R}^{3}$ substituent effect for boroisoquinolines 18 . 

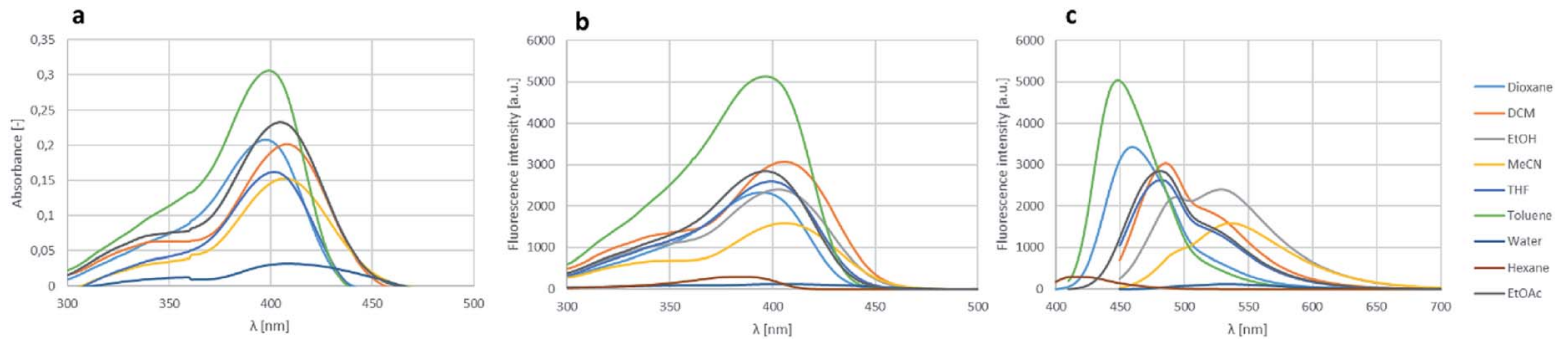

Fig. 6 Solvent screen for the absorbance (a), excitation (b) and fluorescence (c) of $18 \mathrm{l}$.

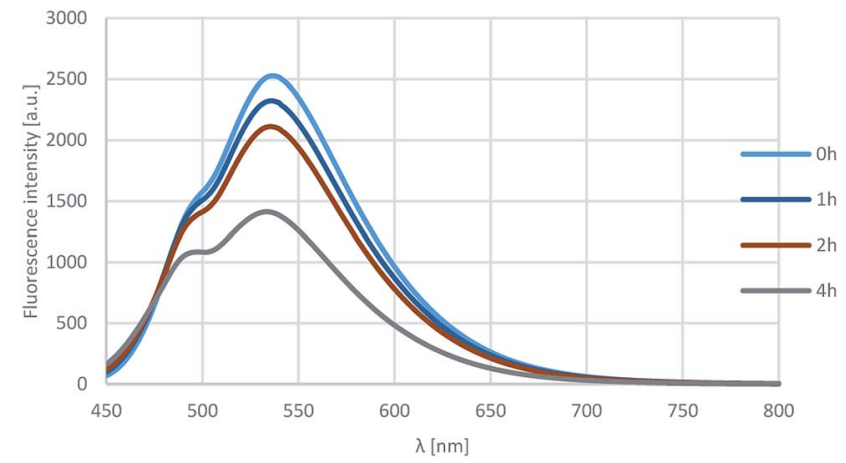

Fig. 7 Results of the photostability test.

(Fig. 6). The solvent screen contained hexane, toluene, ethyl acetate, dichloromethane, dioxane, tetrahydrofuran, ethanol, acetonitrile and water. It could be concluded, that the absorbance and excitation spectra remained similar in the different solvents, the absorption maximum was not shifting significantly (Fig. 6a and b, respectively). It should be noted, that the largest intensity was reached in toluene, ethanol, ethyl acetate and dioxane, while in water (or PBS buffer) the absorbance was practically ceased because of aggregation of the molecules. Meanwhile the solvents seemed to influence the fluorescence more significantly (Fig. 6b).

The measured intensities were similar for the different solvents than those by the absorbance measurements, but in most solvents except MeCN and EtOH the fluorescence maximum decreased to the range under $500 \mathrm{~nm}$ narrowing the room between the excitation and the fluorescence. The loss of absorbance and fluorescence in aqueous medium might be an advantage targeting a protein in an aprotic environment e.g. in the cell membrane, if the fluorescence gets enhanced reaching the target, while stay hidden in the aqueous environment outside the membrane.

Furthermore, the photostability of compound 181 was investigated by measuring the fluorescence in acetonitrile after $0,1,2$ and $4 \mathrm{~h}$ of irradiation with $360 \mathrm{~nm}$ light. As shown on Fig. 7, the fluorescence intensity was still around $60 \%$ after $4 \mathrm{~h}$, that corresponds to outstanding photostability.

Compounds showing outstanding Stokes-shift were studied forward measuring molar absorptivity $(\varepsilon)$ and quantum yield $\left(\Phi_{\mathrm{F}}\right)$ (Table 5). It was found, that some of the boroisoquinolines, particularly $\mathbf{1 8 b}$ and $\mathbf{1 8 l}$ showed more than 0.3 (entries 1,4 ) and a remarkable quantum yield of 0.84 belonged to $18 \mathbf{k}$ (entry 2). On the contrary, the fully aromatic 19c (entry 10) and the perfluorophenyl derivatives $(\mathbf{1 8 g}, \mathbf{h}, \mathbf{m}$; entries $6-8)$ has lower $\Phi_{\mathrm{F}}$ than 0.1 , that might be explained with the dissipation of the electrons on the extended aromatic system, and the large, shielding substituents on the boron atom, respectively. Notably, the pyrrolidine substituent was advantageous for the $\varepsilon$ and $\Phi_{\mathrm{F}}$, but the larger substituents on either the carbonyl group or the boron atom decreased the above values, presumably because of the too extended electron system.

In order to find a possible biological application, compound 18h was reacted with $N$-acetylcysteine (23), as a thiol-surrogate in DMSO at $37^{\circ} \mathrm{C}$. The full conversion was reached after $72 \mathrm{~h}$ and the adduct was isolated in a yield of $75 \%$ (Scheme 4 ). It was

Table 5 Molar absorptivity and quantum yield for selected boroisoquinolines

\begin{tabular}{|c|c|c|c|c|c|c|c|}
\hline Entry & & $\lambda_{\mathrm{abs}}^{\max }[\mathrm{nm}]$ & $\lambda_{\text {exc }}^{\max }[\mathrm{nm}]$ & $\lambda_{\mathrm{em}}^{\max }[\mathrm{nm}]$ & $\Delta \lambda[\mathrm{nm}]$ & $\varepsilon\left(\lambda_{\mathrm{abs}}^{\max }\right)\left[\times 10^{4} \mathrm{M}^{-1} \mathrm{~cm}^{-1}\right]$ & $\Phi_{\mathrm{F}}{ }^{a}[-]$ \\
\hline 1 & $18 \mathrm{~b}$ & 321 & 339 & 431 & 110 & 2.20 & 0.32 \\
\hline 2 & 18k & 383 & 379 & 450 & 67 & 5.47 & 0.84 \\
\hline 4 & 181 & 408 & 406 & 537 & 129 & 3.58 & 0.35 \\
\hline 5 & 211 & 417 & 415 & 544 & 127 & 3.71 & 0.17 \\
\hline 6 & $18 \mathrm{~g}$ & 334 & 343 & 435 & 101 & 2.75 & 0.0024 \\
\hline 9 & $22 b$ & 357 & 368 & 465 & 108 & 3.16 & 0.11 \\
\hline 10 & $19 \mathrm{c}$ & 378 & 372 & 487 & 109 & 2.47 & 0.016 \\
\hline
\end{tabular}

${ }^{a}$ Quantum yields relative to quinin sulfate (dyes 18b,g, 22b) or to Coumarin 153 (dyes 18k,d,l,g,h,m, 19c, 21l, 22b). 


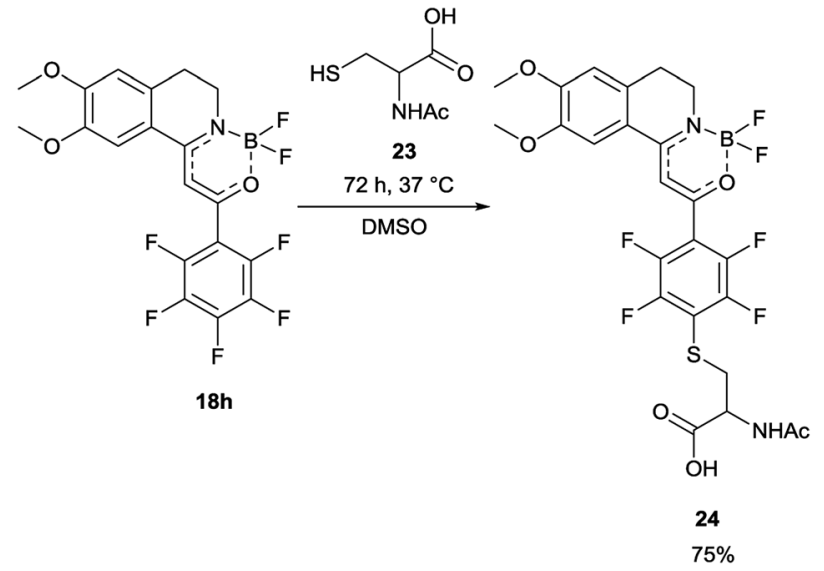

Scheme 4 Reaction of $18 \mathrm{~h}$ with $N$-acetylcysteine (23), as thiolsurrogate.

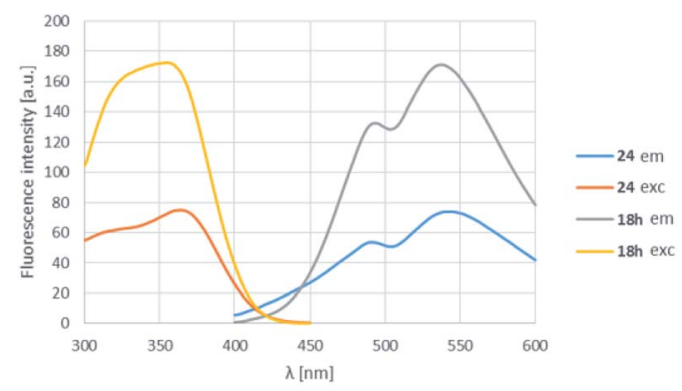

Fig. 8 The change of the excitation and fluorescence spectra in the reaction of $18 \mathrm{~h}$ with $\mathrm{N}$-acetylcysteine (23).

proven, that the thiol group reacted with a fluorine atom on the aromatic ring. The photophysical properties of the conjugate were investigated, and although the intensity of the fluorescence was decreased, the shape of the excitation and fluorescence curve and the Stokes-shift remained similar (Fig. 8). Although the reaction conditions are not yet compatible with the conditions in human cells, this preliminary result projects that after careful optimization these compounds might be applicable for the covalent labelling of cysteines in proteins.

\section{Conclusions}

A new family of fluorophores, namely boroisoquinolines was developed, synthesized from 1-methyl-3,4-dihydroisoquinolines in a two or three step synthesis. The photophysical properties of the small library were extensively studied, and outstanding Stokes shifts with good molar absorptivity values were observed. Some of the dyes $(\mathbf{1 8 b}, \mathbf{k}, \mathbf{l})$ showed appreciable to excellent quantum yields with good photostability. The solvent screening results indicated low fluorescence in aqueous medium that might serve as an advantage using the compounds in aprotic conditions e.g. in cell membranes. We believe that upon further optimization these fluorescent dyes might be good choices for visualization of the labelling of the appropriate proteins (e.g. $\mathrm{CB}_{2}$ ).

\section{Conflicts of interest}

There are no conflicts to declare.

\section{Acknowledgements}

P. Á.-B. is grateful for the postdoctoral fellowship of the Hungarian Academy of Sciences and the Hungarian Science Foundation (OTKA PD124598).

\section{Notes and references}

1 K. W. Bentley, Chemistry and Biochemistry of Organic Natural Products, in The Isoquinoline Alkaloids, Hardwood Academic, Amsterdam, 1998, vol. 1.

2 K. W. Bentley, Nat. Prod. Rep., 2006, 23, 444-463.

3 D. L. Custódio and V. Florêncio Da Veiga Junior, RSC Adv., 2014, 4, 21864-21890.

4 M. Iranshahy, R. J. Quinn and M. Iranshahi, RSC Adv., 2014, 4, 15900-15913.

5 J. A. Joule, M. Alvarez and M. Salas, Heterocycles, 1991, 32, 759.

6 M. S. Pathy and A. J. Reynolds, Postgrad. Med. J., 1980, 56, 488-490.

7 T. Schmeller, B. Latz-Brüning and M. Wink, Phytochemistry, 1997, 44, 257-266.

8 J. E. Park, T. D. Cuong, T. M. Hung, I. Lee, M. Na, J. C. Kim, S. Ryoo, J. H. Lee, J. S. Choi, M. H. Woo and B. S. Min, Bioorg. Med. Chem. Lett., 2011, 21, 6960-6963.

9 W. J. Kong, X. Y. Xing, X. H. Xiao, Y. L. Zhao, J. H. Wei, J. B. Wang, R. C. Yang and M. H. Yang, Appl. Microbiol. Biotechnol., 2012, 96, 503-510.

10 M. Wu, J. Wang and L. T. Liu, Chin. J. Integr. Med., 2010, 16, 188-192.

11 Q. Zhang, X. L. Piao, X. S. Piao, T. Lu, D. Wang and S. W. Kim, Food Chem. Toxicol., 2011, 49, 61-69.

12 S. Kang, Z. Li, Z. Yin, R. Jia, X. Song, L. Li, Z. Chen, L. Peng, J. Qu, Z. Hu, X. Lai, G. Wang, X. Liang, C. He and L. Yin, Nat. Prod. Res., 2015, 29, 2203-2206.

13 K. Bhadra and G. S. Kumar, Med. Res. Rev., 2011, 31, 821862.

14 T. Yoshioka, M. Murai and H. Tasaki. European Patent EP2572717 (B1), 2016.

15 H. Tanihara, T. Inoue, T. Yamamoto, Y. Kuwayama, H. Abe, A. Fukushima, H. Suganami and M. Araie, Acta Ophthalmol., 2016, 94, e26-e34.

16 H. Hidaka, US Pat. US20080064681 (A1), 2008.

17 P. Cheng, N. Huang, Z.-Y. Jiang, Q. Zhang, Y.-T. Zheng, J.-J. Chen, X.-M. Zhang and Y.-B. Ma, Bioorg. Med. Chem. Lett., 2008, 18, 2475-2478.

18 P. Kumar, K. N. Dhawan, K. Kishor, K. P. Bhargava and R. K. Satsangi, J. Heterocycl. Chem., 1982, 19, 677-679.

19 S. Urverg-Ratsimamang, P. Rasoanaivo, H. Rafatro, B. Robijaona and A. Rakato-Ratsimamanga, Ann. Trop. Med. Parasitol., 1994, 88, 271-277.

20 D. Kaufmann, A. Kaur Dogra, A. Tahrani, F. Herrmann and M. Wink, Molecules, 2016, 21, 1161. 
21 L. T. Liu, Y.-C. Lin, C.-L. J. Wang, M.-S. Lin, S.-C. Yen and H.-J. Chen, Bioorg. Med. Chem. Lett., 1996, 6, 1335-1338.

22 R. Gitto, M. L. Barreca, L. De Luca, G. De Sarro, G. Ferreri, S. Quartarone, E. Russo, A. Constanti and A. Chimirri, J. Med. Chem., 2003, 46, 197-200.

23 A. Ohtake, M. Ukai, T. Hatanaka, S. Kobayashi, K. Ikeda, S. Sato, K. Miyata and M. Sasamata, Eur. J. Pharmacol., 2004, 492, 243-250.

24 R. Naito, Y. Yonetoku, Y. Okamoto, A. Toyoshima, K. Ikeda and M. Takeuchi, J. Med. Chem., 2005, 48, 6597-6606.

25 M. Ogawa, Y. Takaoka and A. Ohhata. WO0210135 (A1), 2002.

26 M. Ogawa, Y. Takaoka and A. Ohhata, US. Pat. US2004007643 (A1), 2004.

27 A. Ohhata, Y. Takaoka, M. Ogawa, H. Nakai, S. Yamamoto and H. Ochiai, US Pat. US20050222138 (A1), 2005.

28 K. Raitio, O. Salo, T. Nevalainen, A. Poso and T. Jarvinen, Curr. Med. Chem., 2005, 12, 1217-1237.

29 K. Murtagh, B. A. Sweetman and P. J. Guiry, Pure Appl. Chem., 2006, 78, 311-320.

30 Z. Ma, J. Ding, B. Zhang, C. Mei, Y. Cheng, Z. Xie, L. Wang, X. Jing and F. Wang, Adv. Funct. Mater., 2010, 20, 138-146.

31 D. Frath, S. Azizi, G. Ulrich, P. Retailleau and R. Ziessel, Org. Lett., 2011, 13, 3414-3417.

32 J. Massue, D. Frath, G. Ulrich, P. Retailleau and R. Ziessel, Org. Lett., 2012, 14, 230-233.

33 L. Zhou, D. Xu, H. Gao, A. Han, Y. Yang, C. Zhang, X. Liu and F. Zhao, RSC Adv., 2016, 6, 69560-69568.

34 L. F. Minuti, M. G. Memeo, S. Crespi and P. Quadrelli, Eur. J. Org. Chem., 2016, 821-829.

35 H. Doušová, P. Šimůnek, N. Almonasy and Z. Růžičková, J. Organomet. Chem., 2016, 802, 60-71.
36 S. M. Elbert, P. Wagner, T. Kanagasundaram, F. Rominger and M. Mastalerz, Chem.-Eur. J., 2017, 23, 935-945.

37 U. Balijapalli and S. K. Iyer, Eur. J. Org. Chem., 2015, 50895098.

38 M. Urban, K. Durka, P. Jankowski, J. Serwatowski and S. Luliński, J. Org. Chem., 2017, 82, 8234-8241.

39 D. Frath, K. Benelhadj, M. Munch, J. Massue and G. Ulrich, J. Org. Chem., 2016, 81, 9658-9668.

40 F. Haraszti, T. Igricz, G. Keglevich, M. Milen and P. AbranyiBalogh, Curr. Org. Chem., 2018, 22, 912-922.

41 J. Václavík, J. Pecháček, B. Vilhanová, P. Šot, J. Januščák, V. Matoušek, J. Přech, S. Bártová, M. Kuzma and P. Kačer, Catal. Lett., 2013, 143, 555-562.

42 R. Soni, F. K. Cheung, G. C. Clarkson, J. E. D. Martins, M. A. Graham and M. Wills, Org. Biomol. Chem., 2011, 9, 3290.

43 M. Langlois, B. Bremont, S. Shen, A. Poncet, J. Andrieux, S. Sicsic, I. Serraz, M. Mathe-Allainmat, P. Renard and P. Delagrange, J. Med. Chem., 1995, 38, 2050-2060.

44 R. D. Larsen, R. A. Reamer, E. G. Corley, P. Davis, E. J. J. Grabowski, P. J. Reider and I. Shinkai, J. Org. Chem., 1991, 56, 6034-6038.

45 V. M. Manninen, W. A. E. Omar, J. P. Heiskanen, H. J. Lemmetyinen and O. E. O. Hormi, J. Mater. Chem., 2012, 22, 22971.

46 L. Teuber and J. Larsen. WO 2004/087690 (A2), 2004.

47 T. Di Franco, M. Stojanovic, S. C. Keller, R. Scopelliti and X. Hu, Helv. Chim. Acta, 2016, 99, 830-847.

48 G. Dannhardt, A. Bauer and U. Nowe, J. Prakt. Chem., 1998, 340, 256-263. 